Paper-Calculating the Economic Viability of Corporate Trainings (Traditional \& eLearning) using Benefit Cost Ratio (BCR) and Return On Investment (ROI)

\title{
Calculating the Economic Viability of Corporate Trainings (Traditional \& eLearning) using Benefit-Cost Ratio (BCR) and Return On Investment (ROI)
}

\author{
https://doi.org/10.3991/ijac.v12i1.9735 \\ Srichand Devarakonda $(\bowtie)$ \\ Independent Researcher \\ dnahceers@gmail. com
}

\begin{abstract}
The intent of this paper is fourfold: (a) to document chronologically the history of corporate training; (b) to discuss the importance of corporate training highlighting the reasons why eLearning is gaining traction; (c) to report the results of a research study conducted with 85 sales employees in a U.S.-based organization; and (d) to calculate the return on investment (ROI) for the training costs incurred by the company and validate if the training was economically viable. Forty-two employees received the Traditional mode of training and the remaining 43 received the eLearning mode. The researcher made several comparisons. First, pre-training test scores were compared to posttraining test scores to determine differences between training modes (Traditional or eLearning). Second, post-training test scores of Traditional vs. eLearning mode were compared to determine differences between the modes of training. Third, pre-training sales numbers were compared to post-training sales numbers to determine differences between training modes (Traditional or eLearning). Finally, post-training sales numbers of Traditional vs. eLearning mode were compared to determine differences between training modes. Previous researchers have compared pre- and posttest scores. Some have documented the cost-benefit analysis of training programs and described the ROI percentage achieved from training. However, previous researchers have not detailed the exact dollar value of the benefits achieved from training programs, discussed actual sales numbers, or discussed actual revenue data to show how these were used for tangible ROI in dollar value. To the author's knowledge, this will be the first peer-reviewed study to document, describe, and calculate the aforementioned details.
\end{abstract}

Keywords - Training Evaluation; Business Viability; Economic Viability; Return on Investment (ROI); Corporate Trainings; eLearning; Companies; Corporations; Organizations; Benefit Cost Ratio (BCR); Program Benefits.

\section{Introduction}

Chief Financial Officer: "What happens if we train the employees and they leave?" Chief Executive Officer: "What happens if we don't and they stay?"

-Unknown 
Paper-Calculating the Economic Viability of Corporate Trainings (Traditional \& eLearning) using Benefit Cost Ratio (BCR) and Return On Investment (ROI)

These statements point towards the dilemma with regards to training in any corporation. Historically, corporate learning has occurred through on-the-job training or apprenticeships, in which a "newbie" is trained by a veteran. In objective fields like mathematics, accounting, or medicine, in which only one or two solutions to a problem exist, one-on-one training yields good results. However, in subjective fields like stock investments, sales, and the like, in which there can be numerous ways to solve a problem, one-on-one training often produces inconsistent results. Because each apprentice is only as good or as bad as the veteran he or she trains under, inconsistencies in task performance may occur.

McKinsey (2010) reported that "inconsistent processes across business units yield inconsistent results" (p.4) [1]. Such inconsistencies may prove costly to a corporation's brand image or competitive edge. Ducoff (2013) noted that training is both nonnegotiable and necessary to eliminate costly inconsistencies in organizational performance [2]. Employees need training to understand how the enterprise system will change business processes [3]. Burke and Hutchins (2008) observed that corporate leaders strive for knowledgeable and skilled employees in order to improve performance [4].

A dilemma arises: Company leaders might not train employees because they fear employees might leave. However, employees sometimes leave because they do not receive training. If companies offer training, employees are more likely to remain [5]. For example, in a 2015 survey by West UC's Digital Media Services, two out of three employees said that training played an important role in their decision to stay with the company and three out of four employees had participated in job-related training within the last year, a clear indication that corporations have been moving in the right direction [6]. In addition, with training, employees can master different areas, thereby becoming cross-functional. Training gives employees the tools to succeed. In fact, training employees provides corporations with a competitive advantage (Blackler, 1995) [7].

The goal of any organization is to ensure every employee is aligned with the strategic goals of the company. The key driver to ensure this alignment of the goals is training. According to Rivera and Paradise (2006), organizations that successfully link corporate strategy with learning objectives show increased performance from their learning investments [8]. Nda and Fard (2013) confirm that, in order to maintain sustainability, organizational leaders must see continuous employee training and development as invaluable [9].

\section{$2 \quad$ Literature Review}

\subsection{How Have U.S. Companies Invested in Learning?}

According to the Staff of the Training Industry Report (2017), U.S. companies spent and $\$ 90.6$ billion on training 2017, a 32.5\% increase over previous year. (p.21) [10]. 
Paper-Calculating the Economic Viability of Corporate Trainings (Traditional \& eLearning) using Benefit Cost Ratio (BCR) and Return On Investment (ROI)

Average training expenditure for large companies (10,000+ employees) increased from $\$ 14.3$ million in 2016 to $\$ 17$ million in 2017 . This number remained flat for midsize companies (1,000-9,999 employees) at $\$ 1.5$ million for both the years. And it rose to $\$ 1$ million in 2017 from \$376,251 in 2016 for small companies (100-999 employees) (p.22) [10].

The average training expenditure per learner for 2016 and 2017 was $\$ 814$ and $\$ 1075$ respectively (p.23) [10]. In 2017, 36\% of the companies reported increased training budgets, compared to $37 \%$ in 2016 (p.25) [10]. These companies attributed the increased training budgets to increased scope of training programs, increased number of learners, and purchase of new technologies (p.25) [10]. However, 49\% of the companies reported no change in 2017, compared 50\% in 2016. Also, for 2017, $15 \%$ of the companies reported a decrease, compared to $13 \%$ in 2016 (p.25) [10]. These companies attributed the decreased training budgets to reduced training staff, fewer trainings, and "other" as the reason for this decrease (p.26) [10].

\subsection{Modes of Learning Used}

According to Li, Lau, and Dharmendran (2009), "E-learning is the delivery of a learning, training or education program by electronic means" (p.37) [11]. Applying this definition to the findings of the 2016 Training Industry Report, 46.4\% of small companies, $47 \%$ of midsize companies, and $44.2 \%$ of large companies used virtual classroom, computer-based, online, and mobile training. In contrast, $42.9 \%$ of small companies, $43.2 \%$ of midsize companies, and $39.5 \%$ of large companies used the instructor-led delivery method. Blended learning (part instructor-led, part eLearning) was measured at $42 \%$ for small companies, $41 \%$ for midsize companies, and $21 \%$ for large companies (p.28) [10].

\subsection{Pros and Cons of Traditional (Classroom) vs. ELearning (Online)}

Freifeld (2014) feels that, eLearning has the reputation of being more costeffective, compared to classroom training [12]. Classroom training entails additional expenditures not directly related to knowledge transfer. For example, U.S. companies in 2017 , spent $\$ 44.5$ billion on "other training expenditures" such as travel, facilities, and equipment (p.21) [10]. However, Wentworth (2016) noted that unlike Traditional mode of training, eLearning training was the most expensive to create, costing an average of $\$ 53,742$ per course [13].

Freifeld (2014) reasoned that companies prefer eLearning for cost-effectiveness. Learners can revisit the eLearning courses as many times as desired for refresher purposes [12], unlike in the instructor-led mode, for which companies pay thousands of dollars for participants' travel, conference rooms, food, and hotel rooms to retrain employees. ELearning eliminates such overhead costs associated with Traditional training.

However, findings from Sikora and Carroll (2002) show that learners are less satisfied with eLearning mode compared to Traditional mode. [14] While Traditional 
Paper-Calculating the Economic Viability of Corporate Trainings (Traditional \& eLearning) using Benefit Cost Ratio (BCR) and Return On Investment (ROI)

mode may be slightly more expensive to be used for multiple sessions, the instructor is an expert in the field and can train the learners better than self-paced eLearning. The demonstrations, role-plays and discussions etc. that take place in a classroom setting are invaluable. Instructor led trainings ensures that the objectives of the training are uniformly understood. In eLearning, everyone's understanding of the same topic can be incongruous, and this may prove disastrous for the organization image or bottomline. Also, according to Martinez (2003), eLearning mode has a higher attrition rates (dropout) compared to Traditional mode. [15] The challenge is to keep the online learners engaged by developing an attrition management plan. Many organizations are finding ways to reduce the dropout rates by improving course content, interface design, activities, or a reward for completion etc.

Some of the advantages of Traditional mode of training are consistency of the knowledge transfer and any additional or newinformation, changes, and examples etc. can be communicated extemporaneously. In eLearning mode, learners may derive the meaning of the topic differently and therefore the content has to be proofread by multiple parties before being deployed to the leaners. Also, any change to the course content has to be done by the Learning Management System (LMS) administrator, which could take days or weeks.

Traditional training is a better approach for companies with a smaller or local presence. ELearning training is a major money saver for corporations with global presence, where, neither location nor language will be a barrier because the same course content can have subtitles in various languages.

ELearning is largely independent learning and therefore helps silent participants who are "quiet in meetings other for different reasons, are reticent by nature, fearful that their opinions may be ridiculed, some are not comfortable speaking if they don't know everyone" (para.1) [16]. For such silent participants, eLearning can be a secure and smooth experience [16]. But, most learners might feel isolated in an eLearning environment. Traditional mode allows social participation, enabling face-to-face conversations, discussions, role-plays, simulations, with the instructor or unknown people, thereby creating sense of community and networking opportunities, unlike eLearning. And, may also provide an opportunity for introvert participants to open up and become more sociable.

\subsection{What the Management Wants}

Top executives seek to understand impacts and ROI data. A major study, supported by ASTD, showed that the CEOs' primary desire was to quantify business impact from implementing learning and development [17]. Ninety-Six Fortune 500 CEOs revealed that their second most-desired measure was ROI. At the same time, these executives indicated that the current level of measurement fell far short of showing the desired data. Only $8 \%$ said that they were able to see current business impact $-96 \%$ wanted to see it but could not. For ROI, 4\% were able to see current ROI, and 74\% wanted to see it in the future [18].

Unfortunately, many middle managers lack knowledge to evaluate the effectiveness and Return on Investment (ROI) from training to present to top management. Thus, 
Paper-Calculating the Economic Viability of Corporate Trainings (Traditional \& eLearning) using Benefit Cost Ratio (BCR) and Return On Investment (ROI)

most managers deal only with before-and-after scores, although there are many models that prescribe appropriate testing procedures.

\subsection{Evaluating Results \& Effectiveness}

The term 'evaluation' can be explained differently by different researchers. And one of the reason why Dr. Kirkpatrick developed this model was to articulate the term 'evaluation.' [19]

Kirkpatrick (1994) says that "The reason for evaluating is to determine the effectiveness of a training Program". [19] Evaluation of a training program provides insights into various gamut of business. While training for knowledge transfer, evaluation is a like a confirmation that knowledge transfer did occur and how it has impacted the organization, as a whole. Evaluation brings tangibility to many elements involved in a Training program.

There are many evaluation models that have been mentioned in literature, namely the Kirkpatrick's Four Levels of Evaluation Model [19], the CIRO Model [20], the CIPP Model [21], the Brinkerhoff Model [22], and the Phillips Model [23] [24]. For the purpose of the study the author chose the Kirkpatrick's Four Levels of Evaluation Model and the Phillips Model.

Level 1: Measure of Learners' Reactions to the Course.

- This is commonly done using Post course surveys and questions aboutcourse setting, course content, delivery style, materials, interactions etc.

Level 2: Measure of What They Learned.

- This is typically done comparing pretest and posttest scores.

Level 3: Measure of Changes in the Learners' Behavior, Post Training.

- This level requires supervisor's or peers' assessment that they have noticed a behavior change in the learner.

Level 4: Business Impacts That Occur Because They are Doing Their Jobs Differently.

- This level assesses the Business Impact to the organization, as a whole.

According to U.S. Office of Personnel Management, has the learning "yield[ed] measurable results that directly contribute to accomplishment of the [organization's] goals and ultimate mission". [25]

Phillips (1997a, 1997b, 2016) recommended an additional level, the Level 5, to Kirkpatrick's model. [23] [24] [26] The Level 5 measures the Return on Investment (ROI).

Phillip's Level 5: ROI, calculated by converting productivity and improvements to monetary values

- In plain terms, it measures the success of the training initiative in economic terms. [26] 
Paper-Calculating the Economic Viability of Corporate Trainings (Traditional \& eLearning) using Benefit Cost Ratio (BCR) and Return On Investment (ROI)

\subsection{How Organizations Evaluate Trainings}

Organizational leaders are reluctant to spend money on employee training because they are not positive they will recover their investment. Other reasons for this decision could include high employee turnover rate, quality of available training, and lack of tools to measure the effectiveness and ROI on training. Additionally, Wentworth (2016) noted training is a corporation's biggest budget line item [13]. Accounting departments view training as an expense rather than as an investment [27]. Companies are not required to report training expenditures as a discrete item, therefore it is lumped in with other overhead costs.

Organizations that spend a lot of money on trainings do not quantify their learning results as deeply as Level 4 or Level 5, despite having the evaluation models as guide posts. Evaluating to Levels 1, 2, and 3 provides insight into employees' learning and behavioral changes. The analysis of results from Levels 4 and 5 is the substantiating factor, showing top executives the financial gains and losses from the training.

However, Purcell (2000) opined that organizations do not measure results at Level 4, because "only programs that address a high-risk business issue or have the greatest impact on the bottom line should receive this level of evaluation" (p.32) [28]. The reason that companies do not evaluate at Level 5 is because, quantifying training results is not an easy task. Bernstein and Beeferman (2015) note that "This is an understandable approach since the payoff to training is difficult for an individual company to quantify" (p.13) [27]. When organizations have the necessary tools to quantify training and are doing it for the first time, Phillips (1996) suggested "only one course [metric] should be selected for a calculation as part of the ROI learning curve" (p.4) [29].

\section{Purpose of Study}

According to a 2009 report by ASTD, "Ninety-two percent of respondents to ASTD's Value of Evaluation report indicated that they measure at least Level 1 (reactions of participants) of the model. However, use of the model drops off dramatically with each subsequent level, with only 18\% measuring at Level 5 (return on investment)" (para.2) [30]. The author searched hundreds of peer-reviewed papers and determined that none of the papers have evaluated past Levels 2 or 3 . Even those papers that have evaluations at Level 5, only discussed the cost-benefit analysis - for example, "the training caused a $10 \%$ increase in sales revenue." Glaringly missing from these papers is the "how". None of these hundreds of papers discuss the actual revenue calculations, actual data, and more importantly how the dollar value or increase percentages were achieved. Probably, organizations do not report actual numbers because of competition and thus, no peer-reviewed papers exist today in the entire research databases, which have documented real data and ROI and BCR calculations. This is the first ever study to detail both BCR and ROI for a training exercise of a company, using actual data and calculations and percentages. The caveat being, the company in this study requested to be anonymous due to the aforementioned competitive reasons. 
Paper-Calculating the Economic Viability of Corporate Trainings (Traditional \& eLearning) using Benefit Cost Ratio (BCR) and Return On Investment (ROI)

Research Question \#1.1:

Test Scores: Pre-Training Test Scores vs. Post-Training Test Scores

H10: There is no significant difference between the Pre-Training Test Scores vs.

Post-Training Test Scores.

H1a: There is a significant difference between the Pre-Training Test Scores vs. Post-

Training Test Scores.

Research Question \#1.2:

Test Scores: Classroom vs. Online

H20: There is no significant difference between the test scores of Classroom mode vs. Online mode.

$\mathbf{H 2} \mathbf{2}_{\mathbf{a}}$ : There is a significant difference between the test scores of Classroom mode vs.

Online mode.

Research Question \#2.1:

Pre-Training Sales Figures Vs. Post-Training (either Classroom or Online)

Sales Figures

H30: There is no significant difference between the Pre-Training Sales Figures vs.

Post-Training Sales Figures (either Classroom or Online).

H3a: There is a significant difference between the Pre-Training Sales Figures vs.

Post-Training Sales Figures (either Classroom or Online)

Research Question \#2.2:

Post-Training Sales Figures of Classroom vs. Online

H40: There is no significant difference between the Post-Training Sales Figures of Classroom vs. Online.

H4a: There is a significant difference between

\section{$4 \quad$ Methodology}

- The study was conducted at a U.S. based health food company

- $15 \%$ phone sales and $85 \%$ ecommerce sales

- Teams: Customer Service, Sales, Retention, and Technical Support

- Sales team was trained: 85 Sales associates (with similar pc or sales skills)

- Mode of Training: Traditional or eLearning

- Associates were selected via Lottery Method (42 for Traditional \& 43 for eLearning)

- 16 hours training and 1-hour proctored exam

- The exam (one-hour duration) was not included in the ROI calculation

- Traditional mode attendees had a 2 (two) day class

- eLearning mode attendees had access to the Learning Management System for 1 (one) month

- Associates were unaware that they were being evaluated, therefore, we could not do a survey at the end

- Only the 3 main big-ticket products that the company sold were considered for this research and they were priced at $\$ 250, \$ 350$, and $\$ 450$ 
Paper-Calculating the Economic Viability of Corporate Trainings (Traditional \& eLearning) using Benefit Cost Ratio (BCR) and Return On Investment (ROI)

- $\quad$ There were no new promotions and campaigns by the company, during pretraining and post-training periods of evaluation

\section{$5 \quad$ Results and Discussion}

\section{Research Question \#1.1:}

From Table 1, since the employees were the same individuals tested under two different conditions (Pre-Training and Post-Training) on the same dependent variable (test score), a Paired Samples t-test was used to determine whether there was a statistically significant mean difference between the pre-training test scores $(M=77.66$ and $\mathrm{SD}=10.954)$ and post-training test scores $(\mathrm{M}=80.55$ and $\mathrm{SD}=10.599)$. Employees had better test Post-Training test scores as compared to the Pre-Training test scores. The Post-Training exam showed a statistically significant increase in test scores compared to the Pre-Training exam, $\mathrm{t}(84)=-32.665, \mathrm{p}=0.000$.

The Effect size was estimated using Cohen's d [31], where Cohen's d formula for Paired Samples t-test is: $\mathbf{d}=\mathbf{M} 2-\mathbf{M} 1 / \mathbf{S D}_{\text {pooled }}\left(\right.$ where, $\left.\mathbf{S D}_{\text {pooled }}=\sqrt{ }\left(\left(\mathbf{S D 1}^{\mathbf{2}}+\mathbf{S D 2} \mathbf{2}^{2}\right) / \mathbf{2}\right)\right)$

Cohen's d was estimated at 0.3 , which is in between small to medium effect according to Cohen (1988). [31] [32] [33] [34] H1 1 a).

\section{Normalized Gain}

Hake (1998), introduced the formula for Normalized Gain also known as Learning Gain. [35] In simple terms it is the calculation of how much score a student could have gained from a pre-assessment to post-assessment.

\section{Formula for Normalized Gain:}

(Post-assessment - Pre-assessment) /(100\% - Pre-assessment)

And, the Average Normalized Gain Score, which is an average for the 85 students' individual scores, was 0.1827 . In other words, there was an $18.27 \%$ average normalized gain for the entire class.

\section{Research Question \#1.2:}

From Table 2, since the employees were tested under two unrelated testing conditions (Classroom and Online) on the same dependent variable (test score), an Independent Samples t-test was used to determine whether there was a statistically significant mean difference between the Classroom test scores ( $\mathrm{n} 1=42, \mathrm{M}=80.12$ and $\mathrm{SD}=10.035)$ and Online test scores $(\mathrm{n} 2=43, \mathrm{M}=80.98$ and $\mathrm{SD}=11.226)$. There was statistically no significant difference in test scores between the Classroom and Online participants, $\mathrm{t}(83)=-3.71, \mathrm{p}=0.712$.

The Effect size was estimated using Hedges' g, where Hedges' g formula for Independent Samples t-test is:

$$
\begin{aligned}
& \text { Hedges' } \mathrm{g}=(\mathbf{M} 2-\mathbf{M} 1) / \mathbf{S D}_{\text {pooled }} \\
& \mathbf{S D}_{\text {pooled }}=\sqrt{ }\left(\left(\mathbf{S D 1}^{2}+\mathbf{S D 2}^{2}\right) / \mathbf{2}\right) \\
& \text { Where; }
\end{aligned}
$$

- $\quad$ M2 - M1 = difference in means.

- $\quad \mathrm{SD}_{\text {pooled }}=$ pooled and weighted standard deviation. 
Paper-Calculating the Economic Viability of Corporate Trainings (Traditional \& eLearning) using Benefit Cost Ratio (BCR) and Return On Investment (ROI)

The Effect size was estimated using Hedges $g$ at 0.08 , which is a small effect according to Hedges \& Olkin (1985). [36]

Therefore, we can reject the Alternate hypothesis $\left(\mathrm{H} 2_{\mathrm{a}}\right)$ and accept Null Hypothesis $\left(\mathrm{H} 2_{0}\right)$.

\section{Research Question \#2.1:}

From Table 3, since the employees were the same individuals tested under two different conditions (Pre-Training and Post-Training) on the same dependent variable (sales figure), a Paired Samples t-test was used to determine whether there was a statistically significant mean difference between the Pre-Training sales figures $(\mathrm{M}=$ 64.46 and $\mathrm{SD}=14.788)$ and Post-Training sales figures $(\mathrm{M}=67.18$ and $\mathrm{SD}=13.466)$. Employees had better Post-Training sales figures as compared to the Pre-Training sales figures. The Post-Training sales figures showed a statistically significant increase compared to the Pre-Training sales figures, $\mathrm{t}(84)=-8.824 .665, \mathrm{p}=0.000$.

The Effect size was estimated using Cohen's d, where Cohen's d formula for Paired Samples t-test is: $\mathbf{d}=\mathbf{M} 2-\mathbf{M} 1 / \mathbf{S D}_{\text {pooled }}\left(\right.$ where, $\left.\mathbf{S D}_{\text {pooled }}=\sqrt{ }\left(\left(\mathbf{S D 1}^{2}+\mathbf{S D 2}{ }^{2}\right) / \mathbf{2}\right)\right)$

Cohen's d was estimated at 0.2 , which is a small effect according to Cohen (1988). [31] [32] [33] [34]

Therefore, we can reject the null hypothesis (H30) and accept Alternate Hypothesis (H3a).

\section{Research Question \#2.2:}

From Table 4, since the employees were tested for application of knowledgegained from under two unrelated testing conditions (Classroom and Online) on the same dependent variable (sales figures), an Independent Samples t-test was used to determine whether there was a statistically significant mean difference between the sales figures of the Classroom participants $(\mathrm{n} 1=42, \mathrm{M}=66.36$ and $\mathrm{SD}=13.911)$ and sales figures of the Online participants $(\mathrm{n} 2=43, \mathrm{M}=67.98$ and $\mathrm{SD}=13.132)$. There was statistically no significant difference in sales figures between the Classroom participants and Online participants, $\mathrm{t}(83)=-5.52, \mathrm{p}=0.582$.

The Effect size was estimated using Hedges' g, where Hedges' g formula for Independent Samples t-test is with where $\mathrm{n} 1=$ :

$$
\begin{aligned}
& \text { Hedges' } g=(\mathbf{M} 2-\mathbf{M} 1) / \mathbf{S D}_{\text {pooled }} \\
& \mathbf{S D}_{\text {pooled }}=\sqrt{ }\left(\left(\mathbf{S D 1}^{2}+\mathbf{S D 2}^{2}\right) / 2\right)
\end{aligned}
$$

Where;

- $\quad$ M2 - M1 = difference in means.

- $\quad \mathrm{SD}_{\text {pooled }}=$ pooled and weighted standard deviation.

The Effect size was estimated using Hedges $g$ at 0.12 , which is a small effect according to Hedges \& Olkin (1985). [36]

Therefore, we can reject the Alternate hypothesis $\left(\mathrm{H}_{4} \mathrm{a}\right)$ and accept Null Hypothesis (H40). 
Paper-Calculating the Economic Viability of Corporate Trainings (Traditional \& eLearning) using Benefit Cost Ratio (BCR) and Return On Investment (ROI)

Financial Calculation:

\begin{tabular}{|l|l|}
\hline Monthly Sales Units BEFORE Training & 5479 units. \\
\hline Total Sales in Dollars BEFORE Training & $\begin{array}{l}(1762 * \$ 250) \\
(2026 * \$ 450) \\
=\$ 1,944,050\end{array}$ \\
\hline Monthly Sales Units AFTER Training & 5710 units \\
\hline Total Sales in Dollars AFTER Training & $\begin{array}{l}(1854 * \$ 250) \\
(2130 * \$ 450) \\
=\$ 2,026,100\end{array}$ \\
\hline Additional Sales Units (AFTER - BEFORE) & 5710 units -5479 units $=231$ units \\
\hline Additional Revenue from the Additional Sales Units & $\$ 82,050$ \\
\hline Company's 5-year average gross profit margin & $49.90 \%$ \\
\hline Gross Profit from the Additional Revenue & $\$ 82050 \mathrm{X} 49.90 \%=\$ 40942.95$ \\
\hline Company's 5-year average Net Income & $16.7 \%$ \\
\hline $\begin{array}{c}\text { Net Income (in the first month AFTER the } \\
\text { training) }\end{array}$ & $\$ 40942.95 \times 16.7 \%=\$ 6837.47$ \\
\hline
\end{tabular}

\section{Training Cost Calculator}

The training calculator is based on the sample Cost Estimating Worksheet Phillips \& Phillips. [26]

\begin{tabular}{|c|c|c|c|}
\hline Items & Description & \begin{tabular}{|l} 
eLearning \\
(Online)
\end{tabular} & Traditional (Classroom) \\
\hline \multicolumn{4}{|l|}{$\begin{array}{c}\text { Logistical } \\
\text { Costs }\end{array}$} \\
\hline & \# of Associates & 43 & 42 \\
\hline & \# of hours & 16 & 16 \\
\hline & Wage/hour/Associates & \$16/hr. & \$16/hr. \\
\hline & $\begin{array}{l}\text { Misc. Cost (travel, food, } \\
\text { printouts, etc.) }\end{array}$ & $\mathbf{0}$ & $\$ 147.62$ pp for 2 days \\
\hline & Sub-Total 1 & $\$ 11,008$ & $\$ 16,952$ \\
\hline \multicolumn{4}{|l|}{ IT Costs } \\
\hline & $\begin{array}{lr}\text { Access to } & \text { Learning } \\
\text { Management } & \text { System } \\
(\text { LMS }) & \\
\end{array}$ & $\$ 99$ & $\mathbf{0}$ \\
\hline & Sub-Total 2 & $\$ 4,257$ & $\mathbf{0}$ \\
\hline \multicolumn{4}{|l|}{$\begin{array}{r}\text { Trainer } \\
\text { Costs }\end{array}$} \\
\hline & Instructor Wages & $\$ 10,000$ & $\$ 12,500$ \\
\hline & Travel, Food, Flight, Car etc. & $\mathbf{0}$ & $\$ 5,000$ \\
\hline & Sub-Total 3 & $\$ 10,000$ & $\$ 17,500$ \\
\hline
\end{tabular}


Paper-Calculating the Economic Viability of Corporate Trainings (Traditional \& eLearning) using Benefit Cost Ratio (BCR) and Return On Investment (ROI)

\begin{tabular}{|l|l|l|l|}
\hline Total & $\$ 25,265$ & $\$ 34,452$ \\
\hline Total Cost of the Training Exercise & $\$ 59,717$ & \\
\hline
\end{tabular}

\section{Benefit Cost Ratio (BCR) \& Return on Investment (ROI) Calculation}

According to Brinkerhoff (1991), ROI (Return on Investment) is the ratio between the cost of a program and the value (monetary) of its outcomes. [37]

The program costs of the combined training were $\$ 59,717$ and the program benefits were $\$ 82,050$ in the first month.

\section{FIRST METHOD:}

BCR $=$ Program Benefits $/$ Program Costs $=\$ \mathbf{8 2 0 5 0} / \mathbf{\$ 5 9 7 1 7}=1.37$

As this calculation shows, for every $\$ 1$ invested returns $\$ 1.37$ in benefits.

Thus, the ROI would be:

$$
\begin{aligned}
& \text { ROI }=\text { Net Benefits } / \text { Program Costs X } 100 \\
& \text { Where, Net Benefits }=\text { Program Benefits }- \text { Program Costs } \\
& \quad=\$ 82050-\$ 59717 / \$ 59717 \times 100=37.4 \%
\end{aligned}
$$

This means that, for each $\$ 1$ invested in the program, the ROI is $\$ 1.374$.

\section{SECOND METHOD:}

However, according Knight (2015), the most common mistake that experts make is to calculate ROI using the sales revenues, whereas, net profit is a more accurate approach. [38] The company makes a net profit of $16.7 \%$ on its gross profit of $\$ 40942.95$, resulting in an additional net profit of $\$ 6837.47$ in the first month after the training.

According to Nayab \& Richter (2010), ROI can be calculated monthly too. [39]

\section{ROI $_{\text {Monthly }}=$ Monthly Net Profit $/$ Program Cost X 100}

$=\$ 6837.47 / \$ 59717$ X $100=11.45 \%$ per month.

Thus, the annual ROI is calculated as follows:

ROI $_{\text {Annual }}=$ ROI $_{\text {Monthly }} X 12$ months

$=11.45 \mathrm{X} 12$ (months) $=137.4 \%$.

This means that, for each $\$ 1$ invested in the program, the ROI is $\$ 1.374$.

The author therefore is able to prove using two different methods that the ROI was similar, irrespective of training mode.

\section{Limitations of the Study}

1. Only BCR/ROI was considered. Intangible benefits were not taken into account.

2. Only the sales from the 3 main products that the company sold were taken into consideration.

3. The entire year was not considered for the BCR/ROI calculations, only the pre-training and post-training months' sales figures were taken into account. 
Paper-Calculating the Economic Viability of Corporate Trainings (Traditional \& eLearning) using Benefit Cost Ratio (BCR) and Return On Investment (ROI)

4. Market conditions were stable during the study. When the market conditions are good, people make expensive purchases and hold off during bad market times.

5. Teams received other trainings too, which could result in overlapped benefits.

\section{Conclusion}

The findings of this study corroborate other published literature and research showing that a trained team produces better results than does an untrained one, irrespective of the training mode. Additionally, our research deduced that eLearning mode is equally effective as the Traditional mode.

Many organizations find it sufficient to measure their training programs from Levels 1 through 4 using subjective key performance indicators (KPI) such as customer satisfaction, employee morale, and process improvement. It is tedious to evaluate and apportion how these subjective KPIs contribute to the ROI of the training program. Thereby, resulting in very few papers published, which discuss evaluating training programs at Level 5 (ROI) results. But even these papers only discuss "what" results were achieved.

The current paper will be the first ever in the entire peer-reviewed research database to show not only "what" results were achieved but also "how" the results were achieved.

Notwithstanding the complexities of training, it is an indisputable fact that the true success of training is represented in learners' ability to transfer the learning to their jobs and thereby making profit to the company. The only way to know this is, if organizations start accounting for the time, resources, and money spent on training programs, not as an expense but as an investment. And like any investment, success and failure of training programs should be evaluated in monetary (ROI) terms, which is the key to an organization's survival. 
Paper-Calculating the Economic Viability of Corporate Trainings (Traditional \& eLearning) using Benefit Cost Ratio (BCR) and Return On Investment (ROI)

\section{Tables}

Table. 1

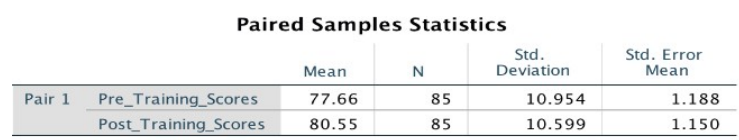

\begin{tabular}{|c|c|c|c|c|}
\hline \multicolumn{5}{|c|}{ Paired Samples Correlations } \\
\hline & & $\mathrm{N}$ & Correlation & Sig. \\
\hline Pair 1 & $\begin{array}{l}\text { Pre_Training_Scores \& } \\
\text { Post_Training_Scores }\end{array}$ & 85 & .998 & .000 \\
\hline
\end{tabular}

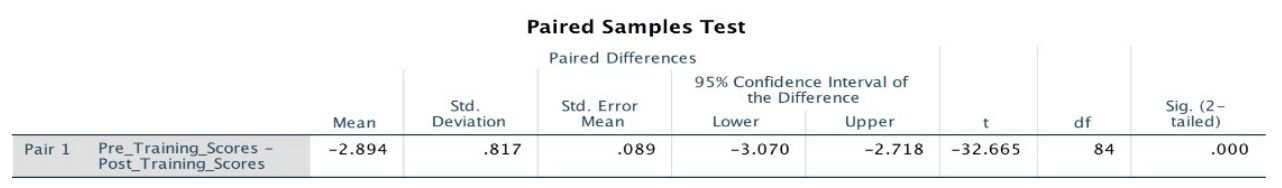

Table 2.

\begin{tabular}{|c|c|c|c|c|c|}
\hline \multicolumn{6}{|c|}{ Group Statistics } \\
\hline & Mode & $\mathrm{N}$ & Mean & $\begin{array}{c}\text { Std. } \\
\text { Deviation }\end{array}$ & $\begin{array}{l}\text { Std. Error } \\
\text { Mean }\end{array}$ \\
\hline \multirow[t]{2}{*}{ Post_Training_Scores } & Class & 42 & 80.12 & 10.035 & 1.548 \\
\hline & Online & 43 & 80.98 & 11.226 & 1.712 \\
\hline
\end{tabular}

\begin{tabular}{|c|c|c|c|c|c|c|c|c|c|c|}
\hline \multicolumn{11}{|c|}{ Independent Samples Test } \\
\hline & & \multicolumn{2}{|c|}{$\begin{array}{c}\text { Levene's Test for Equality of } \\
\text { Variances }\end{array}$} & \multicolumn{7}{|c|}{ t-test for Equality of Means } \\
\hline & & \multirow[b]{2}{*}{$\mathrm{F}$} & \multirow[b]{2}{*}{ Sig. } & \multirow[b]{2}{*}{$t$} & \multirow[b]{2}{*}{ df } & \multirow{2}{*}{$\begin{array}{l}\text { Sig. (2- } \\
\text { tailed) }\end{array}$} & \multirow{2}{*}{$\begin{array}{c}\text { Mean } \\
\text { Difference }\end{array}$} & \multirow{2}{*}{$\begin{array}{l}\text { Std. Error } \\
\text { Difference }\end{array}$} & \multicolumn{2}{|c|}{$\begin{array}{l}\text { 95\% Confidence Interval of } \\
\text { the Difference }\end{array}$} \\
\hline & & & & & & & & & Lower & Upper \\
\hline \multirow[t]{2}{*}{ Post_Training_Scores } & $\begin{array}{l}\text { Equal variances } \\
\text { assumed }\end{array}$ & .823 & .367 & -371 & 83 & .712 & -.858 & 2.311 & -5.455 & 3.740 \\
\hline & $\begin{array}{l}\text { Equal variances not } \\
\text { assumed }\end{array}$ & & & -.372 & 82.361 & .711 & -.858 & 2.308 & -5.449 & 3.734 \\
\hline
\end{tabular}


Paper-Calculating the Economic Viability of Corporate Trainings (Traditional \& eLearning) using Benefit Cost Ratio (BCR) and Return On Investment (ROI)

\section{Table 3.}

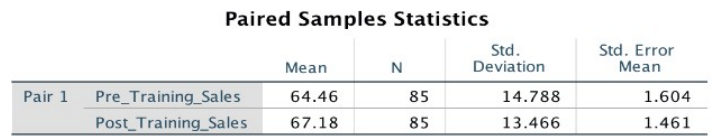

\begin{tabular}{ll|r|r|r}
\multicolumn{8}{c}{ Paired Samples Correlations } \\
& & N & Correlation & \multicolumn{1}{c}{ Sig. } \\
\hline Pair 1 & $\begin{array}{l}\text { Pre_Training_Sales \& } \\
\text { Post_training_Sales }\end{array}$ & 85 & .984 & .000 \\
\hline
\end{tabular}

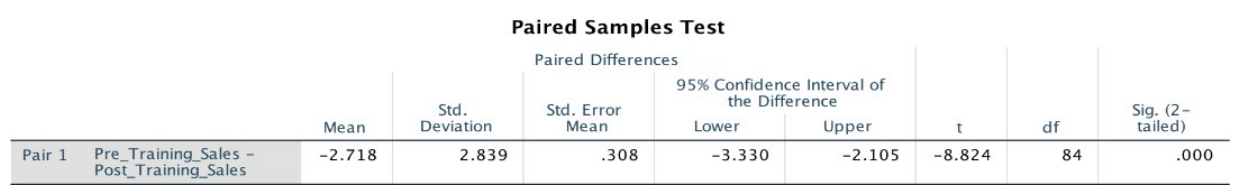

Table 4.
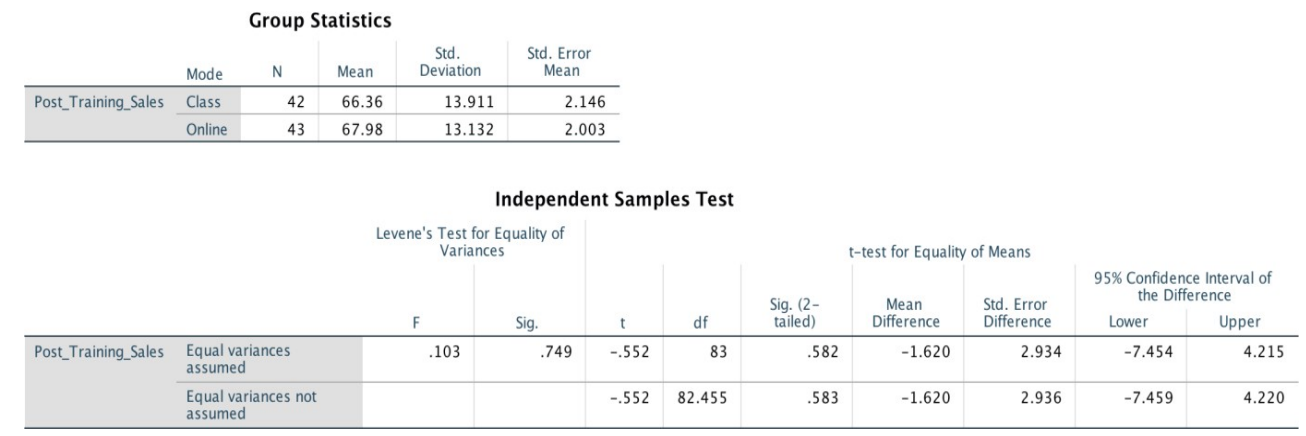

9 References

[1] Beier, N., Harreis, H., Poppensieker, T., Sojka, D., \& Thaten, M. (2010). Getting to grips with counterparty risks. McKinsey \& Company. Available: https://www.mckinsey.com/ /media/mckinsey/dotcom/client service/Risk/Working\%20pa pers/20_Getting_Grips_Counterparty_Risk.ashx. (Accessed on 29 November 2016). https://doi.org/10.17323/1814-9545-2011-2-5-122

[2] Ducoff, N. (2013). How to avoid inconsistency in the workplace. Strategies.com. Available: http://www.strategies.com/blog/how-to-avoid-inconsistency-in-the-workplace/. (Accessed on 20 February 2016).

[3] Fui-Hoon Nah, F., Lee-Shang Lau, J., \& Kuang, J. (2001). Critical factors for successful implementation of enterprise systems. Business process management journal, 7(3), (293). (Accessed on 11 March 2016). https://doi.org/10.1108/14637150110392782 
Paper-Calculating the Economic Viability of Corporate Trainings (Traditional \& eLearning) using Benefit Cost Ratio (BCR) and Return On Investment (ROI)

[4] Burke, L. A., \& Hutchins, H. M. (2008). A study of best practices in training transfer and proposed model of transfer. Human resource development quarterly, 19(2), (107-128). (Accessed on 8 March 2016). https://doi.org/10.1002/hrdq.1230

[5] Hamori, M., Cao, J., \& Koyuncu, B. (2012). Why top young managers are in a nonstop job hunt (No. hal-00779318). Available: https://hbr.org/2012/07/why-top-young-managers-arein-a-nonstop-job-hunt. (Accessed on 4 July 2016).

[6] Rich, K. (2015). State of Employee Training (Infographic). Available: https://www.westuc.com/en-us/blog/webinars-enterprise-streaming/state-employeetraining-infographic. (Accessed on 2 September 2016).

[7] Blackler, F. (1995). Knowledge, knowledge work and organizations: An overview and interpretation. Organization studies, 16(6), 1021-1046. (Accessed on 20 April 2016). https://doi.org/10.1177/017084069501600605

[8] Rivera, R. J., \& Paradise, A. (2006). State of the industry in leading enterprise. Alexandria, VA: ASTD Press. (Accessed on 22 July 2016).

[9] Nda, M. M., \& Fard, R. Y. (2013). The impact of employee training and development on employee productivity. Global Journal of Commerce and Management Perspective, 2(6), 91-93. (Accessed on 20 November 2016).

[10] Staff (2017). 2017 Training Industry Report. Trainingmag.com. Available: https://pubs.royle.com/publication/?i=448382\#\{\%22issue id $\% 22: 448382, \% 22$ page $\% 22: 2$ 2\}. (Accessed on 2 June 2018).

[11] Li, F. W., Lau, R. W., \& Dharmendran, P. (2009). A three-tier profiling framework for adaptive e-learning. Proceedings of the 8th International Conference on Advances in Web Based Learning, Aachen. (Accessed on 2 January 2017).

[12] Freifeld, L. (2014). Online In-Class Success. Trainingmag.com. Available: http://www.cedmaeurope.org/newsletter\%20articles/Training\%20Magazine/Online\%20versus\%20InClass\%20Success\%20(Sep\%2014).pdf (Accessed on 20 December 2017).

[13] Wentworth, D. (2016). Training Budget Benchmarks and Optimizations for 2017. Brandon Hall Group. Available: http://www.litmos.com/wp-content/uploads/2016/12/BHG-trainingbudget-benchmarks-report-2017.pdf (Accessed on 16 March 2017). https://doi.org/10.18411/a-2017-023

[14] Sikora, A. C., and Carroll, C. D. (2002). Postsecondary education descriptive analysis reports (NCES 2003-154). US Department of Education, National Center for Education Statistics. Washington, DC.: US Government Printing Office. (Accessed on 22 August 2016). https://doi.org/10.1037/e492162006-002

[15] Martinez, M. (2003). High attrition rates in e-learning: Challenges, predictors, and solutions. The eLearning Developers Journal, 2(2), 1-7. (Accessed on 22 August 2016).

[16] Paris, K. (n.d). Silent Participants: Common Meeting Problems. Office of Human Resource Development. University of Wisconsin, Madison. Available: https:/www.talent.wisc.edu/academicleadershipsupport/LeadMeetings/tabid/74/Default.as px (Accessed on 29 November 2016).

[17] Phillips, J. J., \& Phillips, P. P. (2009). Measuring for success: What CEOs really think about learning investments. American Society for Training and Development. (Accessed on 17 April 2016).

[18] Phillips, J. J., \& Phillips, P. P. (n.d). Global Trends in L\&D Analytics. Trainingmag.com. Available: https://rainingmag.com/trgmag-article/global-trends-ld-analytics (Accessed on 17 April 2016). 
Paper-Calculating the Economic Viability of Corporate Trainings (Traditional \& eLearning) using Benefit Cost Ratio (BCR) and Return On Investment (ROI)

[19] Kirkpatrick D.L (1994). Evaluating Training Programs: The Four Levels. San Francisco, CA: Berrett-Koehler Publishers, Inc. (Accessed on 3 April 2016). https://doi.org/10.1016/s1098-2140(99)80206-9

[20] Warr, P., Bird, M., \& Rackham, N. (1970). Evaluation of management training. London: Gower Press. (Accessed on 26 January 2016).

[21] Stufflebeam, D.L. (1971). The relevance of the CIPP evaluation model for educational accountability. Journal of Research \& Development in Education, 5(1), 19-25, F71. (Accessed on 26 January 2016).

[22] Brinkerhoff, R. (1988). An integrated evaluation model for HRD. Training and Development Journal, 42(2), 66-68. (Accessed on 2 June 2016).

[23] Phillips, J. J. (Ed.). (1997a). In action: Measuring return on investment, Vol. 2. (pp. 87-98). Alexandria, VA: American Society for Training \& Development. (Accessed on 24 May 2016).

[24] Phillips, J. J. (1997b). Return on Investment In Training and Performance Improvement, Programs. Houston: Gulf. (Accessed on 24 May 2016).

[25] United States Office of Personnel Management (USOPM). Training Evaluation Field Guide: Demonstrating the Value of Training at Every Level. Washington, DC: USOPM, 2011. Available: $\quad$ https://www.opm.gov/policy-data-oversight/training-anddevelopment/reference-materials/training_evaluation.pdf (Accessed on 17 September 2016).

[26] Phillips, J. J., \& Phillips, P. P. (2016). Handbook of training evaluation and measurement methods. Fourth Edition Routledge. (Accessed on 24 May 2016).

[27] Bernstein, A., \& Beeferman, L. (2015). The materiality of human capital to corporate financial performance. Available: https://wp.law.harvard.edu/files/lwp/files/pension paper materiality of human capital 0 42015.pdf (Accessed on 2 February 2016). https://doi.org/10.2139/ssrn.2605640

[28] Purcell, A. (2000). 20/20 ROI. Training \& Development, 54 (7), (28-32). (Accessed on 11 October 2016).

[29] Phillips, J. (1996). Measuring ROI: The Fifth Level of Evaluation. Technical \& Skills Training, 7(3), 10-13. (Accessed on 24 May 2016).

[30] ATD Staff. (2009). The Value of Evaluation: Usage and value of Kirkpatrick/Phillips model. Association for Talent Development. Available: https://www.td.org/Publications/Blogs/ATD-Blog/2009/10/The-Value-of-EvaluationUsage-and-Value-of-KirkpatrickPhillips-Model (Accessed on 30 November 2016).

[31] Cohen, J. (1988). Statistical power analysis for the behavioral sciences (2nd ed.). Hillsdale, NJ: Lawrence Erlbaum Associates. (Accessed on 4 July 2016).

[32] Cohen's d effect size table. Available: https://www.uccs.edu/lbecker/effect-size.html (Accessed on 2 December 2016).

[33] Ellis, P.D. (2009), "Thresholds For Interpreting Effect Sizes". Available: http://www.polyu.edu.hk/mm/effectsizefaqs/thresholds for interpreting effect sizes $2 . h t m$ 1 (Accessed on 2 December 2016).

[34] Ellis, P.D. (2009), "Result Whacker", Available: http://www.polyu.edu.hk/mm/effectsizefaqs/calculator/result.html (Accessed on 2 December 2016).

[35] Hake, R. R. (1998). Interactive-engagement versus traditional methods: A six-thousandstudent survey of mechanics test data for introductory physics courses. American journal of Physics, 66(1), 64-74. (Accessed on 15 October 2016).

[36] Hedges, L.V. and I. Olkin (1985), Statistical Methods for Meta-Analysis. London: Academic Press. (Accessed on 18 November 2016). 
Paper-Calculating the Economic Viability of Corporate Trainings (Traditional \& eLearning) using Benefit Cost Ratio (BCR) and Return On Investment (ROI)

[37] Brinkerhoff, R. O. (1991). Achieving results from training. San Francisco: Jossey Bass. (Accessed on 2 September 2017).

[38] Knight, J. (2015). The Most Common Mistake People Make in Calculating ROI. Harvard Business Review. Available: https://hbr.org/2015/04/the-most-common-mistake-peoplemake-in-calculating-roi (Accessed on 22 August 2016).

[39] Nayab, N. and Richter, L. (2010). Learn to Calculate ROI: Formulas and Examples. Brighthub.com. Available: http://www.brighthub.com/office/finance/articles/79132.aspx (Accessed on 29 October 2016).

\section{Authors}

Srichand Devarakonda is an independent researcher.

Article submitted 2018-10-18. Resubmitted 2018-12-14. Final acceptance 2019-01-02. Final version published as submitted by the authors. 